\title{
Es geht auch anders in Frankreich
}

\section{Norbert Lutz}

Dr. med., Mitglied FMH

\author{
Ich habe mit grossem Interesse den Leidensweg meines Freundes Ueli Bollag gelesen \\ und hoffe, es geht ihm wieder gut. Hier nun meine Erfahrung mit der französi- \\ schen Medizin.
}

Ich war schon den ganzen Tag recht müde und bis dann bei guter Gesundheit. Um 1.30 Uhr ging ich noch was holen im Keller meines Ferienhauses. Ich kam jedoch nur bis zur vorletzten Treppenstufe, wo ich kraftlos liegen blieb. Zum Glück hörte meine Frau, dass ich sehr schlecht atmete. Sie konnte mich mit grosser Mühe aus der Treppe holen. Daraufhin rief sie die Notfallnummer 15 an. Diese reagierte schnell und adäquat: Sie schickte die Ambulanz der Feuerwehr (Pompiers mit 3 Personen) und nach Rücksprache den SMUR mit einer Ärztin und einer Krankenschwester. Ich wurde sehr kompetent für den Transport vorbereitet und ins Spital in Gassin geführt.

Nach Abklärungen wurde mir und meiner Frau im Laufe des Morgens mitgeteilt, dass eine Verlegung ins Spital Fréjus, wo eine Intensivstation betrieben wird,

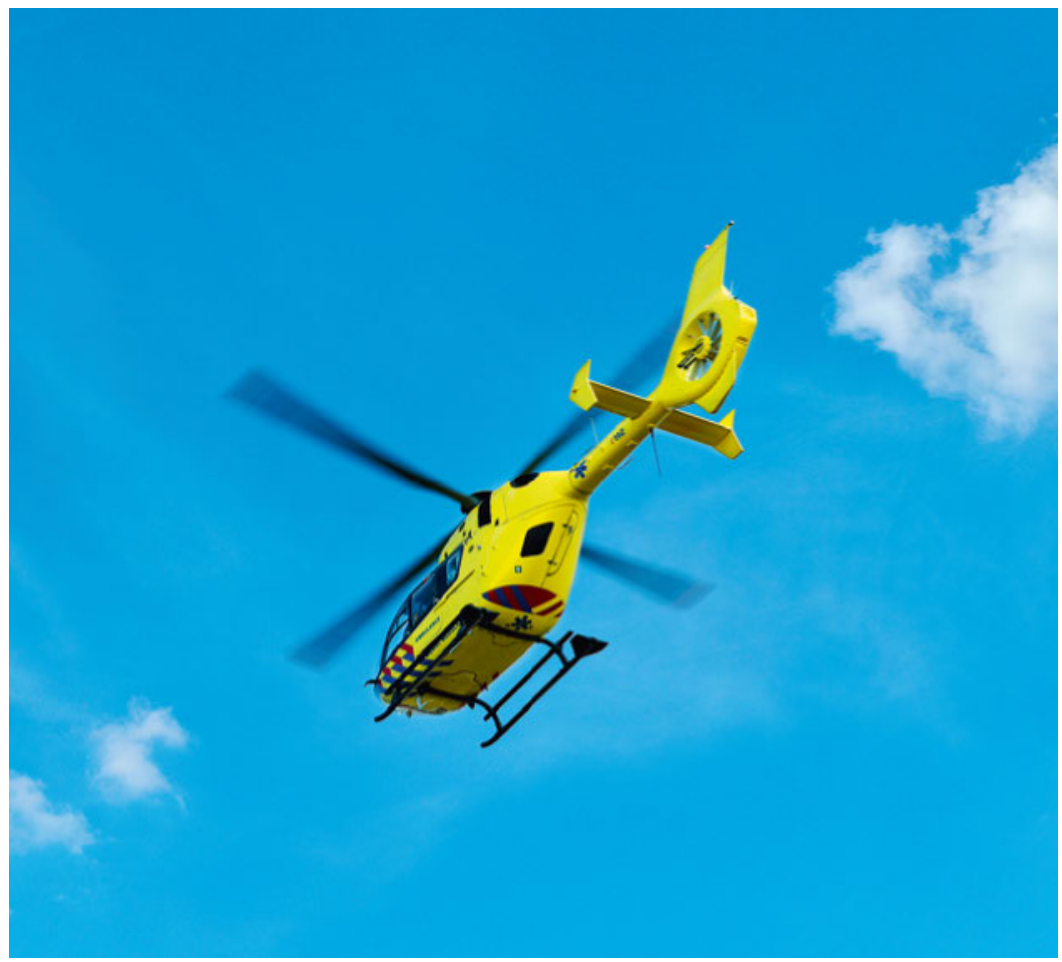

Norbert Lutz wurde mit dem Helikopter vom Spital Gassin nach Fréjus geflogen und auf die dortige Intensivstation verlegt (Symbolbild). notwendig sei. Ich wurde per Helikopter verlegt (der Arzt der Helicrew war ein Berner!), und im Spital Fréjus wurde eine schwere Legionellen-Pneumonie festgestellt. Ich wurde sehr fachmännisch betreut und für

\section{Ich wurde sehr kompetent für den Transport} vorbereitet und ins Spital in Gassin geführt.

zwölf Tage ins künstliche Koma versetzt. Auch laut meiner Frau und meinen Kindern (mein Sohn ist Apotheker) wurde ich sehr gut behandelt.

\section{Zurück in der Schweiz}

Nach Erwachen aus dem Koma wurde ich dann nach vier Intensivstationstagen von der REGA via Sitten nach Visp zurückgeflogen. Nach einer weiteren Woche Intensivstation in Visp ging es dann für drei Wochen in die Rehabilitation nach Brig. Ich habe mich sehr gut erholt und bin wieder bei guter Gesundheit.

\section{Fazit}

Zusammenfassend muss ich sagen, dass ich auf der ganzen Linie sehr gut betreut wurde, sowohl in Frankreich als auch in der Schweiz. So unterschiedlich kann die Betreuung in einem fremden Land sein. Der eine hat Glück, der andere Pech.

\section{Bildnachweis}

(c) Gerardkoudenburg | Dreamstime.com

\section{Wie sind Ihre Erfahrungen?}

Haben Sie sich als Ärztin oder Arzt auch schon unversehens in der Patientenrolle wiedergefunden? Wenn Sie finden, dass Ihre Geschichte für die Leserschaft der SÄZ interessant sein könnte, schicken Sie uns gern einen Artikel mit maximal 8000 Zeichen Umfang an redaktion.saez[at]emh.ch - bei positiver Beurteilung durch die Redaktion wird Ihr Manuskript dann im Rahmen der Serie "Ärztinnen und Ärzte als Patienten» publiziert. 